\title{
The New Dot Context: How to Mitigate Trademark Concerns in ICANN's New gTLD Program
}

\author{
BENJAMIN BOROUGHF*
}

\begin{abstract}
Expanding the Domain Name System without fully addressing the impact on trademark holders is a risk that Internet Corporation for Assigned Names and Numbers ("ICANN") has seemed to embrace. With ICANN's new gTLD program, consumers and companies will soon begin encountering new top-level domains that reflect a company's brand or trademark. Unfortunately, with the inclusion of these so called, brand top-level domains, ICANN is creating potentially disastrous problems for trademark holders, legitimate users, and even consumers: a brand focus limits the use of identical trademarks online and prevents the Domain Name System from having any real and reliable context to distinguish identical trademarks. To mitigate these problems, and to ensure that trademarks can coexist within a trademark-distinguishing context, ICANN should eliminate the brand top-level domain and should focus on context-creating category top-level domains. This Article demonstrates why these problems exist within ICANN's new program and it sets forth a proposal that seeks to mitigate these concerns and to realign the new program with ICANN's own goals.
\end{abstract}

\footnotetext{
* Candidate for Juris Doctor, Chicago-Kent College of Law, Class of 2014. The author wishes to thank Professors Grant Shackelford, Edward Lee, and Hank Perritt for their great support throughout the drafts. The author also wishes to thank Professor Christi Guerrini for helpful comments. Additionally, the author wishes to thank Professor Christopher Seaman for providing invaluable help during the first year writing courses.
} 


\section{INTRODUCTION}

The online world is about to change-for the worse. In 2012, the Internet Corporation for Assigned Names and Numbers ("ICANN") instituted a new policy that expands the range of available generic toplevel domains ("gTLDs") beyond the well-known .com and twenty-one other gTLDs. Unlike its prior expansions of top-level domains, this time ICANN allowed anyone to apply, for a hefty fee of $\$ 185,000$, to register virtually any new top-level domain, such as .goodhands, .love, .here, .ira, .justforu, and .wtf. ${ }^{1}$ The new policy even gave trademark holders the ability to register their trademarks in what are known as brand gTLDs. Not surprisingly, many businesses rushed in to lay claim to their brand. For example, Johnson Shareholdings applied for .afamilycompany, while Guardian Life Insurance and Guardian News have both applied to control .guardian, and Google, Inc. and NTT Resonant, Inc.-a Japanese company operating a search engine located at <www.goo.ne.jp>-have both applied for .goo. ${ }^{2}$ In total, ICANN received over 1,900 applications for more than 1,300 new gTLDs. ${ }^{3}$ Of these applications, nearly 500 involve trademarks. ${ }^{4}$ Soon, the Internet will be filled with trademarks and brand names as gTLDs, including guardian, .delta, .patagonia, and the like.

ICANN's new program is disastrous. When trademarks and brands appear in the top-level domain, they lose their information conveying ability. The consumer has no context to differentiate between identical marks, so confusion will inevitably arise. Who owns $<$ www.news.guardian>-Guardian Life Insurance or Guardian News? What about <www.contact.onyourside>-Channel 7 News or Nationwide Insurance? Or <www.home.delta $>-$ Delta Faucet or Delta Air Lines? Every brand that uses a term which several trademark holders own as trademarks for different markets will inevitably create unwarranted consumer confusion on the Internet.

The lack of context also prevents companies with identical names from having an equal presence on the supposedly expanded domain

\footnotetext{
1 Program Statistics, InTERNET CORPORATION FOR ASSIGNED NAMES AND NuMBERS (2012), http://newgtlds.icann.org/en/program-status/statistics.
2 Reveal Day 13 June 2012 - New gTLD Applied-For Strings, INTERNET CORPORATION FOR ASSIGNED NAMES AND NumBERS (June 13, 2012), http://newgtlds.icann.org/en/programstatus/application-results/strings-1200utc-13jun12-en.
}

3 Program Statistics, supra note 1.

${ }^{4} I d$. 
name space. Once Guardian News obtains the right to .guardian, Guardian Insurance cannot use the same .guardian gTLD. With the potential for companies to control these new .brand gTLD types, certain trademark owners will control far too much of the domain name space-meaning Internet space-at the expense of other legitimate users.

This Note critiques ICANN's new gTLD program and explains why it is a major failure. Applying a linguistic perspective of semiotics, Part I explains how ICANN's policy deprives consumers the ability to differentiate between identical trademarks. Part II proposes a revision to fix ICANN's flawed policy by adopting a categorical bar to all .brand gTLDs. Only generic category gTLDs, such as .news or .construction, are allowed under the proposal. Furthermore, to create the necessary context marketplace for businesses, organizations, and consumers to interact in, ICANN should register certain restricted category-type gTLDs. ICANN should also change its application process and prevent trademark holders from registering new gTLDs during a "Sunrise period," so that companies, organizations, and individuals with identical brands or trademarks will have the ability to develop their own presence in the new expanded Internet. Part III concludes by addressing possible objections.

\section{CANN'S NEW GTLD POLICY AND ITS HARM TO TRADEMARKS}

ICANN's new gTLD Program harms trademarks because it discounts the benefits of the Domain Name System ("DNS") structure, ignores how consumers interact with trademarks and domain names, 5 and exacerbates the problems associated with trademark law's current view of domain names. Today, consumers perceive a connection between the gTLD and the second-level domain. Most consumers believe that a company's main website exists in the .com gTLD,

\footnotetext{
${ }_{5}^{5}$ Katherine Dusak Miller, Preliminary Report of Dennis Carlton Regarding Impact of New gTLD on Consumer Welfare, INTERNET CORPORATION FOR ASSIGNED NAMES AND NUMBERS (March 2009), http://archive.icann.org/en/topics/new-gtlds/prelim-reportconsumer-welfare-04maro9-en.pdf. When a company uses a trademark, the company creates a market identity because a trademark is a symbol, word or group of words that "functions as a source identifier of the goods or services on which the trademark is affixed." Xuan-Thao N. Ngyuen, Cyberproperty and Judicial Dissonance: The Trouble with Domain Name Classification 10 GEO. MASON L. REV. 183, 192 (2001). A company's market identity through the use of a trademark allows consumers to quickly identify the product and the product's source because a trademark "distinguishes its associated goods or services from others." Id.
} 
specifically at <trademark.com $>.^{6}$ Moreover, trademark law does not view gTLDs as serving any source-identifying function. ${ }^{7}$ Yet, the mere use of a trademark in the domain name incites fears of consumer confusion and encourages trademark holders to capture as many domain names as possible to protect their brand. ${ }^{8}$ As a result, in its current state, ICANN's program will significantly reduce the ability of the DNS to foster context-creating top-level domains because it perpetuates these fears and misguided approaches to understanding trademarks in domain names. ${ }^{9}$

\section{A. Trademarks and Domain Names}

Trademark law allows identical marks to coexist when rival uses do not create a likelihood of confusion. ${ }^{\circ}$ For example, both Apple, Inc. and Apple Vacations own the mark "apple." However, Apple, Inc. cannot prevent Apple Vacations from using "apple" because Apple Vacations uses the mark for holiday travel services-a different market

\footnotetext{
${ }^{6}$ Shiveh Roxana Reed, Sensible Agnosticism: An Updated Approach to Domain-Name Trademark Infringement, 61 DUKE L.J. 211, 242 (2011).

7 Brookfield Commc'ns, Inc. v. West Coast Entm’t Corp., 174 F.3d 1036, 1055 (9th Cir. 1999).

8 Image Online Design, Inc. v. Core Ass'n, 120 F. Supp. 2d 870, 878 (C.D. Cal. 2000) (quoting United States Department of Commerce, Patent and Trademark Office, Examination Guide No. 2-99, Marks Composed, in Whole or in Part, of Domain Names (Sept. 29, 1999)).

9 For example, as of January 17, 2013 ICANN has been dealing with Image Online Design, Inc., the trademark holder for WEB, over the use and possible confusion of the .web gTLD. Michael Berkens, ICANN Files Memorandum In Support Of Dismissing Suit Over .Web, THE DomaIns (Jan. 17 2013), http://www.thedomains.com/2013/o1/17/icann-filesmemorandum-in-support-of-dismissing-suit-over-web.

${ }_{10}$ The Lanham Act (15 U.S.C. § 1051-1129). Confusion can arise based on the perceived affiliation or sponsorship of the trademark holder. Michael S. Mireles, Jr, Towards Recognizing and Reconciling the Multiplicity of Values and Interests in Trademark Law, 44 IND. L. REV. 427, 429 (2011). Confusion can also occur when products are similar because "the public will mistakenly assume there is an association between the producers of the related goods, though no such association exists." Miguel C. Danielson, Confusion, Illusion and the Death of Trademark Law in Domain Name Disputes, 6 J. TECH. L. \& POL'Y 219, 228 (2001) (internal quotations omitted). When a consumer mistakenly believes that two companies are interrelated, then that confusion destroys the value of the trademark because trademarks are "intended to point to only one company" in one market. $I d$. at note 257 (internal quotations omitted).
} 
from the computer and electronics market. ${ }^{11}$ On the other hand, identical trademarks have difficulty coexisting online because trademark law views the Internet as a single marketplace. ${ }^{12}$ When online consumers search for a product they must rely on the secondlevel domain name to locate the website and determine its content and sponsorship. ${ }^{13}$ Second-level domain names are valuable because they can "communicate the business of the company to the consumer." 14 As a result, second-level domains have become the primary source of trademark disputes and consumer confusion. ${ }^{15}$

\section{Domain Name System}

At the heart of the problem with ICANN's new gTLD program is the domain name system. The DNS is a hierarchical namespace controlled by ICANN. ${ }^{16}$ It "was developed to associate IP addresses with more memorable domain name addresses consisting of alphanumeric text because" Internet Protocol ("IP") addresses are long, arbitrary, and "nearly impossible for human users to remember." 17 For the DNS to work, IP addresses and domain names

$"$ Graeme B. Dinwoodie \& Mark D. Janis, Confusion Over Use: Contextualism in Trademark law, 92 IOWA L. REV. 1597, 1658 (2007).

${ }^{12}$ Miguel C. Danielson, Confusion, Illusion and the Death of Trademark Law in Domain Name Disputes, 6 J. TECH. L. \& POL’Y 219, 219 (2001).

${ }^{13}$ Jude A. Thomas, Fifteen Years of Fame: The Declining Relevance of Domain names in the Enduring Conflict Between Trademark and Free Speech Rights, 11 J. MARSHALL REv. INTELL. PROP. L. 1, 8 (2011).

${ }^{14}$ Xuan-Thao N. Ngyuen, Cyberproperty and Judicial Dissonance: The Trouble with Domain Name Classification, 10 GEO. MASON L. REV. 183, 190 (2001).

${ }_{5}$ Miller, supra note 5.

${ }^{16}$ In November 1998, the United States created ICANN “as a U.S.-based, nonprofit, private entity" to control the domain name system. ICANN administers the registries that maintains a database of domain names and manages registration within generic top level domains. Ryan R. Owens, Domain-Name Dispute-Resolution After Sallen v. Corinthians Licenciamentos \& Barcelona.com, Inc. v. Excelentisimo Ayuntameiento De Barcelona, 18 BERKELEY TECH. L.J. 257, 260 (2003). Moreover, ICANN approves domain name registrars, accredited companies that register second-level domains. Id.

17 Owens, supra note 16 , at 259. 
must be unique. ${ }^{18}$ The key elements to a domain name are the toplevel domain and the second-level domain. For example, the top-level domain of <www.microsoft.com> is .com, and the second-level is .microsoft. Once an individual registers a second-level domain within a top-level, "no one can register an identical domain name within that top-level domain." 19 In other words, once the combination of SLD.TLD has been registered, that combination cannot be registered again. ${ }^{20}$ So, two individuals cannot each register $<$ www.forexample.com $>$. An individual, however, can register that same second-level domain in another top-level, because the DNS is a hierarchical namespace. So, one individual can register $<w w w . f o r e x a m p l e . c o m>$ and another individual can register $<$ www.forexample.org $>$. What this means is that a hierarchical namespace like the DNS can scale well because "each object must have a unique name only within its subname space in order to have an unambiguously resolvable name within the name space hierarchy." ${ }^{21}$ Conversely, in a flat namespace, when a name is used more than once, "the name space violates the unambiguously resolvable requirement." ${ }_{22}$ Therefore, "[f]lat name spaces do not scale well because they can grow only so large before all available names are used up." ${ }^{23}$ (See Figure 1)

\footnotetext{
${ }^{18}$ Andrew D. Murray, Internet Domain Names: The Trade Mark Challenge, 6 INT'L J.L. INFO. \& TECH. 285, 290 (1998).

19 Owens, supra note 16 , at 260-61.

${ }^{20}$ The Internet DNS "is a complex, leveled system similar to a pyramid. At the apex of the DNS pyramid is the root zone." Brian W. Borchert, Imminent Domain Name: The Technological Land-Grab and Icann's Lifting of Domain Name Restrictions, 45 VAL. U. L. REV. 505, 509 (2011) (footnotes omitted).

${ }^{21}$ Name Space, MiCrosoft DeveloPer NeTWORK (2012), http://msdn.microsoft.com/enus/library/windows/desktop/ms682853\%28v=vs.85\%29.aspx.

${ }^{22} I d$.

$23 I d$.
} 
Figure 1:
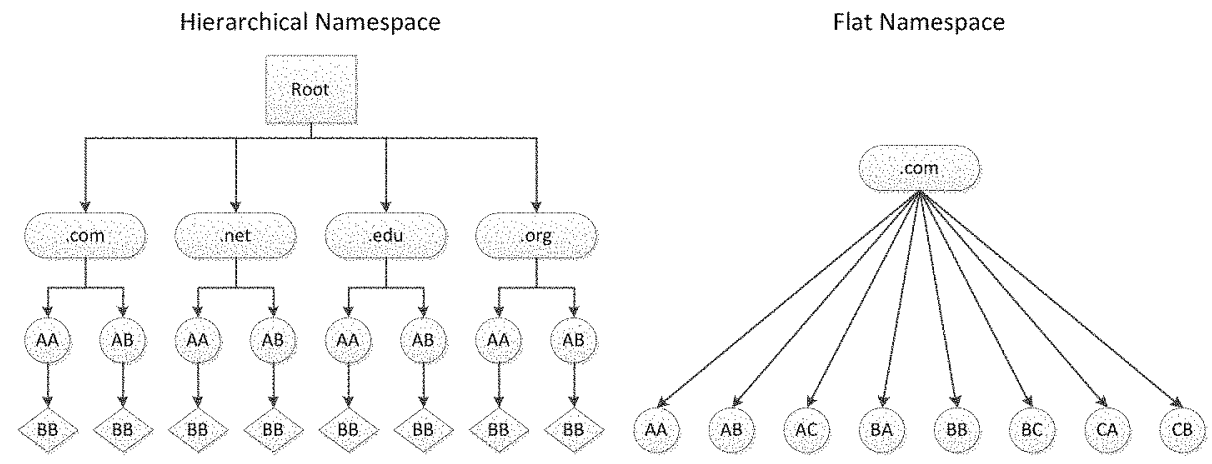

Initially, gTLDs were "intended to be registered and used by specific types of entities." 24 Commercial entities would register under .com, network, infrastructure companies would register under .net, non-profit organizations would register under .org, and education institutions would register under .edu. ${ }^{25}$ Moreover, during the formation of ICANN, commentators argued that even though "businesses must have confidence that their trademarks can be protected" in cyberspace, the DNS must "provide trademark holders with the same rights they have in the physical world."26 The DNS should therefore allow multiple uses of identical trademarks without issue.

Sadly, the DNS currently does not have this context-structure, and this has led to conflicts between trademark holders and registrants. Sponsored gTLDs such as .edu and .travel continue to limit registrants to educational institutions and travel related companies respectively. However, the original open gTLDs like .com do not have any restrictions; the requirements were lost over time because the distinctions were rarely, if ever, enforced. ${ }^{27}$ An additional issue with

24 Connie L. Ellerbach, Domain Name Dispute Remedies: Tools for Taming the World Wide Web, 759 PLI/PAT 513, 516 (2003).

$25 I d$.

${ }^{26}$ Improvement of Technical Management of Internet Names and Addresses, 15 C.F.R. $\S$ 28 (proposed Feb. 20, 1998), available at http://www.ntia.doc.gov/federal-registernotice/1998/improvement-technical-management-internet-names-and-addressesproposed-.

27 Id. 
open gTLDs is that there is no obligation to check if a domain name infringes a company's trademark rights. ${ }^{28}$ Since a registrar's only real obligation is to make sure domain names are unique, the registrars do not have to evaluate and determine who is entitled to the domain name. ${ }^{29}$ Thus, even though the "the desire to make domain names out of easily-remembered product names" has led people to believe .com is the only meaningful gTLD, ${ }^{30}$ companies continue to register their trademarks under as many gTLDs as possible and as quickly as possible to increase their control over their trademark online. ${ }^{31}$ More recently, organizations have been considering how best to protect trademarks in domain names, for example, by requesting ICANN to block their trademarks from appearing in any other URL for a certain fee. ${ }^{2}$

By focusing on registering second-level domains, rather than focusing on the differences between top-level domains, "similarlynamed entities are in conflict even if there would ordinarily be no chance of confusing them in the marketplace."33 Thus, the source of

\footnotetext{
${ }^{28}$ The difficulty of identical or similar trademarks to coexist online "is exacerbated in undifferentiated domains, since similar marks with common elements can coexist in relation to different classes of goods or services without confusion, whereas only one of the owners may use the mark or the common element alone as a domain name in a large undifferentiated domain." The Management of the Internet Names and Addresses: Intellectual Property Issues, INTERNET CORPORATION FOR ASSIGNED NAMES AND NUMBERS (Apr. 30, 1999), http://archive.icann.org/en/wipo/FinalReport_2.html.

29 Ellerbach, supra note 24, at 516.

30 RFC 3467: Role of the Domain Name System, THE INTERNET ENGINEERING TASK FORCE, http://www.rfc-editor.org/rfc/rfc3467.txt (last visited July 23, 2012). In fact, ".com domain names account for a disproportionately high $75 \%$ of all generic TLDs registered." Thomas, supra note 13, at 52.

${ }^{31}$ When companies wish to take their brand to the Internet, they typically use their trademark because consumers can easily remember and identify domain names and because domain names identify the company, its product, and its activities. Michael L. Katz, et al., Economic Considerations in the Expansion of Generic Top-Level Domain Names, Phase II Report: Case Studies, INTERNET CORPORATION FOR ASSIGNED NAMES AND NUMBERS (December 2010), http://archive.icann.org/en/topics/new-gtlds/phase-twoeconomic-considerations-03dec10-en.pdf.

32 Davis, Wendy, Marketers Ask ICANN For Additional Trademark Protections, MEdiaPostNews (Feb 7, 2013), http://www.mediapost.com/publications/article/193039/marketers-ask-icann-foradditional-trademark-prote.html\#axzz2KeUs2HxM.

33 RFC 3467: Role of the Domain Name System, supra note 30.
} 
conflict is the use of the trademark in the domain name regardless of what appears around it, because the trademark holder wishes to maintain its online presence by eliminating any rival from the contextless online marketplace. 34

\section{Enforcement}

To protect its trademark online, a trademark holder must demonstrate a likelihood of confusion between its mark and the use of the mark by another. 35 Online confusion analysis is distinct from an ordinary confusion analysis, in which a trademark holder has the right to use the mark on products sold in the market in which the company does business. ${ }^{36}$ Instead of focusing on how the trademark is used within the domain name, though, trademark law for domain names tends to focus primarily on if the trademark is used. ${ }^{37}$

34 Ellerbach, supra note 24, at 516-17.

35 The Lanham Act defines trademark infringement as the use in commerce, without consent, of "any word, term, name, symbol, or device ... which is likely to cause confusion, or to cause mistake, or to deceive." Confusion in Cyberspace: Defending and Recalibrating the Initial Interest Confusion Doctrine, 117 HARV. L. REV. 2387, 2391-92 (2004) (internal quotations and footnotes omitted).

${ }^{36}$ For example "Dell Computers has an exclusive right to use the mark Dell as a trademark for computer hardware in connection with the sale of Dell-brand computer hardware. It can't stop Dell publishing from using the mark 'Dell' on books, even books about computing." Jessica Litman, The Dns Wars: Trademarks and the Internet Domain Name System, 4 J. SMALl \& EMERGING BuS. L. 149, 153 (2000). However, Dell computers can prevent the use of dell.net because "the use of the first level domain designation '.com' does not in and of itself constitute a commercial use. The Internet is constantly changing and evolving," and .com allows both commercial and private parties to register second-level domains. HQM, Ltd. v. Hatfield, 71 F. Supp. 2d 500, 507 (D. Md. 1999) (quoting Intermatic Inc. v. Toeppen, 947 F. Supp. 1227, 1239 (N.D. Ill. 1996)).

37 For example, see Joseph Dello Russo M.D. v. Michelle Guillaumin, No. D2006-1627 (WIPO 2006) (Bernstein, Arb.),

http://www.wipo.int/amc/en/domains/decisions/html/2006/d2006-1627.html (concluding that even though the registrant used info instead of .com and included subsidiary words in the second level, the registrant misled Internet users because the mark was used in the domain name). See also Société Air France v. Mark Allaye-Chan, No. D2009-0327 (WIPO 2009) (Swinson, Arb.), http://www.wipo.int/amc/en/domains/decisions/html/2009/d2009-0327.html (concluding that when a registrant incorporates a trademark in its entirety in the domain name, the registrant deliberately chooses "a domain name which [is] likely to be confused with the Complainant's trade mark and own domain name," and which increases Internet traffic to the registrant's website because of the likelihood of confusion with the trademark). 
For example, when a trademark holder and a domain name registrant have websites using an identical trademark, courts consider that these are in close proximity because "both sites compete for the same audience-namely, Internet users who are searching for a web site that uses plaintiff's mark." 38 The chance of confusion increases because of "[ $\mathrm{t}]$ his high degree of competitive proximity." 39 Even if the products are ultimately different, "when product proximity is not an issue, courts" may evaluate whether the domain name and the trademark are similar. $4^{\circ}$ Thus, when viewed as a single marketing channel, the Internet "is particularly susceptible to a likelihood of confusion since ... it allows for competing marks to be encountered at the same time, on the same screen." 41

Moreover, trademark law exacerbates this problem by ignoring whether the other letters or words surrounding the trademark create a context to distinguish the trademark..$^{2}$ Courts assess the similarity of a domain name to the trademark by looking at the dominant or salient portions of the domain name; yet, the dominant portion tends to be the trademark itself. 43 In other words, additional words in second-

${ }^{38} \mathrm{OBH}$, Inc. v. Spotlight Magazine, Inc., 86 F. Supp. 2d 176, 188 (W.D.N.Y. 2000).

39 Id.

40 Prime Publishers, Inc. v. Am.-Republican, Inc., 160 F. Supp. 2d 266, 280 (D. Conn. 2001).

${ }^{41}$ GoTo.com, Inc. v. Walt Disney Co., 202 F.3d 1199, 1207 (9th Cir. 2000). For example, when www.plannedpartenhood.com was compared to the trademark "Planned Parenthood," the court found the two marks were nearly identical because "the only distinctions are the latter's lack of initial capitalization, the lack of a space between words, and the '.com' that is necessary to designate a domain name." Planned Parenthood Fed'n of Am., Inc. v. Bucci, 1997 WL 133313 (S.D.N.Y. Mar. 24, 1997) aff'd, 152 F.3d 920 (2d Cir. 1998). Even though there were differences between the trademark and the domain name, the use of the mark made them inconsequential.

${ }^{42}$ Even when a top level domain could function as a market differentiator, Uniform Domain Name Resolution Policy ("UDRP") panels ignore that function. For example, a domain name that used the .tv TLD was still "confusingly similar to the mark" even though :the ccTLD ".tv' clearly lets users know that it is a television-based site, and not a retailer" because "the domain name wholly incorporate[d] the mark" and because "using a different ccTLD does not sufficiently distinguish the name from the mark." Williams-Sonoma Inc. v. Anthony Galima d/b/a Unity 4 Humanity Inc., No. FA0803001163666 (NAF 2008)

(McCotter, Donahey, \& Grossman, Arbs.),

http://domains.adrforum.com/domains/decisions/1163666.htm.

43 Volvo Trademark Holding AB v. Volvospares.com, 703 F. Supp. $2 d$ 563, 568 (E.D. Va. 2010) (internal quotations omitted). 
level domains using trademarks do not reduce confusion because the trademark is the only source of information. ${ }^{44}$ Thus, under current approaches to trademark enforcement in domain names, the mere use of the mark can create chances of consumer confusion.

\section{B. New Policy for gTLDs}

In 2008, ICANN responded to brand protection concerns and to the overreliance on .com by introducing a new gTLD program that attempts to provide trademark holders more control over their brands. The program allows trademark holders to apply for .brand gTLDs which create a single, secure, and protected location for their brand. 45 This seems to encourage a more structured and hierarchical DNS. Supporters state that "to the extent that the introduction of new gTLDs gives rise to intellectual property concerns, they can be addressed through existing procedures for protecting intellectual property." 46 Critics respond that the program will only increase consumer confusion 47 and that it will increase the costs to enhance a trademark holder's control over its brand online. ${ }^{48}$

\section{Reasons}

ICANN believes the .brand gTLD will benefit trademark owners because they can have a dedicated location to promote their brand. For instance, instead of relying on spreading the trademark across multiple top-level domains, such as .com, .net, .org, and .info, brand

\footnotetext{
44 A \& F Trademark, Inc. v. Jorgensen, No. D2001-0900 (WIPO 2001) (Weinstein, Arb.), http://www.wipo.int/amc/en/domains/decisions/html/2001/d2001-0900.html.

45 Terence P. Ross, Understanding ICANN's New Top-Level Domain Name Program, in Understanding Developments in Cyberspace Law: Leading Laws on Examining Privacy Issues, Addressing Security Concerns, and Responding to Recent IT Trends, *1 2011 WL 3020564 at 1 (Aspatore, July 1, 2011).

${ }^{46}$ Miller, supra note 5 .

47 Graeme B. Dinwoodie, (National) Trademark Laws and the (Non-National) Domain Name System, 21 U. PA. J. INT'L ECON. L. 495, 518 (2000).

${ }^{48}$ Ross, supra note 45 , at 6.
} 
owners would have "more control over their web presence." 49 Plus, .brand gTLDs would allow brand owners to differentiate themselves from other identical or similar online uses of the brand. This will give brand owners "an infinite universe of branded domains that can be used to promote products and services," apart from competitors and companies using identical trademarks. $5^{\circ}$ For example, Apple, Inc. owns <apple.com> and <apple.info>, but has to deal with <apple.org>, which redirects to a website containing information about genetically modified foods. Once Apple, Inc. controls .apple, its consumers may theoretically know that Apple, Inc. is located at that gTLD.

ICANN further believes that .brand gTLDs will provide the "best fraud prevention and trademark protection." ${ }_{11}$ That is, when a trademark holder controls the .brand gTLD and every domain underneath it, the .brand may be devoid of infringing sites, diversion, cybersquatting, and brand abuse. Therefore, ICANN and the .brand applicants believe that "[ $\mathrm{t}]$ his will result in a trusted space where consumers can rely on the notion that, 'if it doesn't end in .ourbrand, it's not a genuine "our brand" website." ${ }_{52}$

\section{Overview of the Registration Process}

To acquire a new gTLD, an established corporation, organization, or institution in good standing must submit an application, pay a fee of $\$ 185,000$, and indicate which type of gTLD it seeks.53 Applicants may choose to apply for a .brand gTLD, such as .kodak; an industry gTLD, such as .bank; a geographic gTLD, such as .Illinois; or a nonLatin script gTLD, such as.コム.54

\footnotetext{
49 Mark V.B. Partridge \& Jordan A. Arnot, Expansion of the Domain Name System: Advantages, Objections and Contentions, 22 DEPAUL J. ART, TECH. \& INTELL. PROP. L. 317, 319 (2012).

$5^{\circ} I d$. (internal quotations omitted).

${ }^{51} \mathrm{Id}$. at 321 .

${ }^{2} I d$.

53 Elizabeth Herbst Schierman, Make Room for .trademark: What You Should Know About the New Global Domain Names, 53 THE ADvocaTe 25, 26 (2010).

54 Mary M. Squyres, The New GTLDs, 172 InTELl. Prop. Couns. 1, 1 (2011).
} 
Each application must also "be marked as an open gTLD or a community-based gTLD." 55 An applicant that chooses an open gTLD may decide to restrict it, excluding competitors or placing "high charges and restrictions on competitors." 56 Unlike an open gTLD, a community gTLD will work like current sponsored gTLDs; the sponsor must use it for the benefit of the defined community. ${ }^{57}$

When an applicant passes the evaluation stages ${ }^{5}$ and enters into an agreement with ICANN, the owner of the new gTLD must agree to provide trademark protection through a mandatory Trademark Claims Service and Sunrise Service Policy for a minimum of thirty days before launch. 59 The Sunrise Policy attempts to enable trademark holders to guard against identical uses of their trademark by "precluding third-parties from registering the identical domain under the gTLD." 60 When a trademark holder places its mark in the Trademark Clearinghouse, ${ }^{61}$ the trademark holder can "register its trademark(s) as an SLD under a newly delegated gTLD" before the registry opens the gTLD to the general public. ${ }^{62}$ Although a trademark holder can object when a third-party files an identical trademark, if that third-party has legitimate rights to the trademark, the trademark

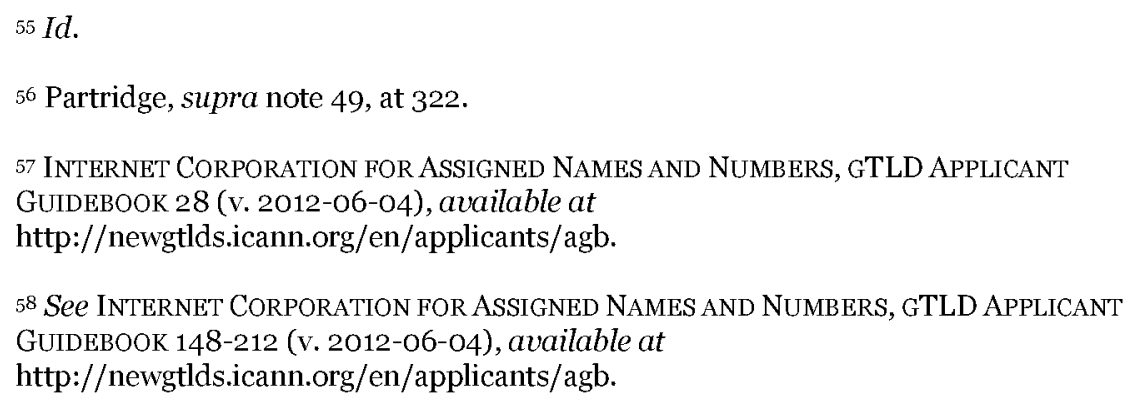

59 The Trademark Claims Service is designed to report to registries domain names are identical matches with the validated marks. INTERNET CORPORATION FOR ASSIGNED NAMES AND NUMBERS, GTLD APPLICANT GUIDEBOOK 295 (v. 2012-06-04), available at http://newgtlds.icann.org/en/applicants/agb.

60 Dennis S. Prahl \& Eric Null, The New Generic Top-Level Domain Program: A New Era of Risk for Trademark Owners and the Internet, 101 TRADEMARK REP. 1757, 1780 (2011).

\footnotetext{
${ }^{61}$ The trademark clearing house will consist of "nationally or regionally registered word marks, word marks that have been validated through a court of law or other judicial proceeding, [and] word marks protected by statute or treaty." INTERNET CORPORATION FOR ASSIGNED NAMES AND NUMBERS, GTLD APPLICANT GUIDEBOOK 292-93 (v. 2012-O6-O4), available at http://newgtlds.icann.org/en/applicants/agb.
}

62 Prahl, supra note 60. 
holder cannot obtain the second-level domain.63 Therefore, once a legitimate mark holder registers its brand as a second-level domain, no other company or rightsholder may attempt to use it for its own legitimate purpose.

\section{Application Results}

The application results reveal that companies are relying on a .brand Internet to form exclusive online presences. Of the 1,930 applications ICANN received, roughly 500 are for company names or brands, company trademark slogans, or company acronyms. ${ }^{64}$ All or almost all of these .brand gTLD applications were applied by the brand owner. ${ }^{65}$ However, the majority of the .brand applications seem to be defensive registrations "without any plans to broadly launch a new gTLD beyond a handful of second-level domains."66 Lastly, 230 gTLD strings have at least two applications, such as Guardian Insurance and Guardian News applying for .guardian. ${ }^{67}$ These .brand applications reveal that the Internet may soon be littered with unique, context-less, and possibly fallow top-level domains.

\section{ICANN's New gTLD Policy Harms Trademarks}

The problem with allowing these unique but context-less gTLDs is that ICANN fails to embrace the chance to use the new program to work toward mitigating the continuation of a context-less DNS. ICANN fails because it does not ensure identical trademarks can

\footnotetext{
${ }^{63}$ INTERNET CORPORATION FOR ASSIGNED NAMES AND NUMBERS, GTLD APPLICANT GUIDEBOOK 296-97 (v. 2012-06-04), available at http://newgtlds.icann.org/en/applicants/agb.

${ }^{64}$ Andrea L. Calvaruso, et al., gTLDs in the running: take a look at the line-up, and what it means for your organization!, LEXOLOGY (June 14, 2012),

http://www.lexology.com/library/detail.aspx?g=078d39ff-e8df-47de-8ded-19692a8ef208.

$65 I d$.

66 Reed Smith, New gTLD Applications Revealed: What Comes Next?, JDSUPRA (June 20, 2012), http://www.jdsupra.com/post/documentViewer.aspx?fid=144ed3b7-22bd-46b8b303-4d944fb7d37f. For example, Johnson \& Johnson registered for .afamilycompany. Application Details: AFAMILYCOMPANY, INTERNET CORPORATION FOR ASSIGNED NAMES AND NUMBERS (2012), http://gtldresult.icann.org/applicationresult/applicationstatus/applicationdetails/1172.

67 Calvaruso, supra note 64.
} 
coexist in the new program. Although .brand applicants have spoken of the benefits of having one secure location to promote their brand, 68 the addition of .brand will reduce the effectiveness of trademarks because consumers will not have the ability to see the trademarks in context. Once a brand owner uses its trademark as a gTLD, the trademark will not work to identify the company because the domain name will not include context-creating elements.

Moreover, the Sunrise Policy encourages a flat DNS namespace. Through this Policy, a trademark holder can register its brand in any available gTLD without objections from other identical brand holders. A trademark holder could register its mark under .music and .car even though it does not do business in the music or car industry. Consequently, even though ICANN permits category-type gTLDs, the Sunrise Policy may prevent the creation of a structured DNS to differentiate between each new gTLD.

\section{ICANN's Allowance of .brand gTLDs Invites Consumer Confusion}

The use of .brand will not decrease the chances of consumer confusion. Once a company registers a .brand gTLD, the company removes any additional words from the domain namespace that consumers could use to determine which company the trademark identifies. ${ }^{69}$ Before ICANN's gTLD program, trademark owners and consumers only had to worry about confusion in the second-level domain. With ICANN's new gTLD program and the inclusion of .brand, though, trademark owners and consumers will now also have to worry about confusion in the top-level domain. Some .brand applicants have tried to dispel these concerns by indicating that their

\footnotetext{
${ }^{68}$ For example, the clothing company, Patagonia, anticipates that consumers "will come to recognize and rely upon the .patagonia TLD as an indication of authenticity that the .patagonia website they locate and interact with is associated with and created by us." Application Details: PATAGONIA, INTERNET CORPORATION FOR ASSIGNED NAMES AND NUMBERS (2012), http://gtldresult.icann.org/applicationresult/applicationstatus/applicationdetails/1466.

69 Frontier's application provides the following examples of planned web addresses: homepage.frontier, toolbar.frontier, frontiersecure.frontier, myaccount.frontier, and customerservice.frontier. Application Details: FRONTIER, INTERNET CORPORATION FOR ASSIGNED NAMES AND NUMBERS (2012), http://gtldresult.icann.org/applicationresult/applicationstatus/applicationdetails/31. Although all examples use the Frontier brand name, the second-level domain does not provide any information as to which Frontier company controls frontier.
} 
.brand gTLD will increase differentiation and decrease brand confusion and inauthenticity or fraud. $7^{\circ}$

But these companies have yet to demonstrate that .brand will promote the source-identifying functions of trademarks. In fact, these companies recognize that .brand focuses on only one use out of the many possible identical uses of the .brand. For example, Guardian Insurance states that .guardian will provide a safe and intuitive means "to find trustworthy information about insurance and financial services." 71 Moreover, the company argues that .guardian "will indicate to consumers that the domains and content are owned and controlled by Guardian, assuring users that they 'are safe from potential infringing, pirated, or harmful content relating to personal and business finances." 72 On the other hand, Guardian News, which has also applied for .guardian, argues that .guardian "will allow web users to easily identify Guardian News and Media sites and services worldwide" and to be secure knowing that the communications and information using the gTLD "originate directly from Guardian News and Media." 73

These two applications demonstrate that .brand gTLDs will not reduce the chances of consumer confusion because when consumers see .guardian they may understand that it refers to the Insurance company or to the News company. Therefore, in registering .brand, the applicants endorse an Internet where consumers will see a trademark but will not know what exactly the .brand refers to. 74

\footnotetext{
${ }^{70}$ According to Delta's Application, "[o]ccupation of a TLD by an individual brand substantially addresses the possibility of error or uncertainty in identification of a brand and its associated services. The consumer is able clearly to differentiate Delta from among all others on the Internet, quickly, simply and reliably." Application Details: DELTA, INTERNET CORPORATION FOR ASSIGNED NAMES AND NUMBERS (2012),

http:/gtldresult.icann.org/application-result/applicationstatus/applicationdetails/11oo.

${ }^{71}$ Application Details: GUARDIAN, INTERNET CORPORATION FOR ASSIGNED NAMES AND NUMBERS (2012), http://gtldresult.icann.org/applicationresult/applicationstatus/applicationdetails/1038.

${ }^{72} I d$.

73 Application Details: GUARDIAN, INTERNET CORPORATION FOR ASSIGNED NAMES AND NuMBERS (2012), http://gtldresult.icann.org/applicationresult/applicationstatus/applicationdetails/430.

74 In fact, ICANN's public comments section is dominated by individuals arguing that Patagonia Inc.'s gTLD creates confusion because individuals will see .patagonia and believe that the gTLD refers to the geographical location instead of the clothing company. Even though trademark law ignores top-level domains, the use of $<$ www.patagonia.com $>$ for
} 


\section{Semiotic Analysis of Trademarks Illuminates the Key Problem}

Unfortunately, the key problem with ICANN's new program is that it focuses too much on the use of the trademark in the top-level domain. Without measures that allow trademark coexistence "while providing users with the information to distinguish between the owners of the similar names," trademark conflict and consumer confusion will not decrease. ${ }^{75}$ A semiotic perspective demonstrates this shortcoming. It explains how consumers interact with trademarks and how ICANN's new gTLD program fosters a flat, context-less Internet that affects the function of trademarks.

When consumers can determine the differences between trademarks, they will not be confused about sponsorship; rather, they will be able to understand which trademark refers to which company. Under the theory of semiotics, a trademark is part of a sign system that works to communicate sponsorship or affiliation to the consumer. ${ }^{76}$ Signs are made up of three elements: the representamen, the interpretant, and the referent. ${ }^{77}$ In terms of trademark law, the representamen is the trademark-word, the interpretant is the goodwill, and the referent is the product or service to which the company attaches the trademark.

Consumers experience similar and different referents and representamen every day. Consumers see multiple shoes and computers, and they see multiple Uniteds, Deltas, Apples, and Guardians. When the referents are similar, the different representamen influences the consumer's interpretation of the object. ${ }^{8}$ However, when the representamen are similar the referents must be different in order to affect the consumer's interpretant, or understanding of which referent refers to which company. In the

\footnotetext{
Patagonia Inc.'s website at least indicates to consumers that the website is for a nongeographical entity.

75 The Management of the Internet Names and Addresses: Intellectual Property Issues, supra note 28 .

${ }^{76}$ Lutz Goetzmann \& Kyrill Schwegler, Semiotic Aspects of the Countertransference: Some Observations on the Concepts of the 'Immediate Object' and the 'Interpretant' in the Work of Charles S. Peirce, 1423 INT'L J. PSYCHOANALYSIS 1426 (2004).

$77 I d$.

${ }^{78}$ For example, consumers understand that Nike shoes are different from Reebok shoes because of the different trademark-representamen.
} 
offline world, referent differentiation exists when they are used in different markets. 79 If a consumer only sees Delta and Delta, the consumer's interpretant may be the same for both companies-the consumer may associate one company with the other. However, if the referents are placed in different markets, such as an airline market and a home furnishing market, the consumer's interpretant differs between the two companies. Thus, the context of different markets enables a consumer to differentiate between trademarks.

On the other hand, with .brand in the online world this ability to differentiate identical trademarks will not exist because .brand gTLDs do not give context to the DNS. Online consumers do not interact with different physical referents; instead, they interact with referentdomain names. ${ }^{80}$ With .brand, chances of consumer confusion will not decrease and consumers will not easily recognize the company, they will see one and only one .brand. Even though "a TLD points to the content of the site," without the ability to compare market differences, trademarks lose their ability to invoke the goodwill of the company in the consumer's mind. ${ }^{81}$ A consumer could examine the content of the website; yet trademarks and domain names were designed to provide consumers with quick and efficient information about the sponsorship or content of the website. ${ }^{82}$ Thus, ICANN should move away from a .brand gTLD focus and should encourage gTLDs that provide the differentiating context necessary for trademarks.

3. Problems with the Application Process: ICANN's Sunrise Policy Exacerbates a Flat Namespace and Promotes Fears of Consumer Confusion

Still, even without .brand gTLDs, ICANN's Sunrise Policy encourages a flat namespace and encourages trademark holders to worry about consumer confusion because it views trademarks as words without a context. The Policy promotes a flat namespace

\footnotetext{
79 See AMF Inc. v. Sleekcraft Boats, 599 F.2d 341, 348 (9th Cir. 1979).

${ }^{80}$ Meghann L. Garrett, Trademarks as a System of Signs: A Semiotic Look at Trademark Law, 61 INT’L J. SEMIOTIC L. 66 (2010).

${ }^{81}$ Image Online Design, Inc. v. Core Ass'n, 120 F. Supp. 2d 870, 879 (C.D. Cal. 2000).

82 Compared to a .brand gTLD, a category gTLD "provides opportunities for enhanced messages online because it conveys immediate information about products and services." Partridge, supra note 49, at 322.
} 
because brand owners who "elect to file defensive registrations during" the Sunrise period "often have little or no use for the domain name that they obtain through these procedures." ${ }_{3}$ Moreover, the Policy fosters fears of consumer confusion because the new unrestricted gTLDs will act similar to current unrestricted gTLDs. Currently, "[m]any trademark owners register common misspellings or derivations of their trademarks and even register the same secondlevel domain names . . . in multiple generic Top-Level Domains." 84 Trademark holders reason that this vigilance will benefit them because they can "capture as much of their intended audience and traffic as possible" and because they can "prevent others from using their brands for negative or critical purposes, including, but not limited to, diverting traffic away from the mark owners." 85 Consequently, the Sunrise Policy does not foster a system in which third-parties can control a domain name and use it for a legitimate purpose. The Policy instead promotes empty areas of the namespace that may be exacerbating the scarcity of second-level domains. ${ }^{86}$

Thus, contrary to ICANN's goals, "adding more open ... gTLDs, is more likely to increase the likelihood of confusion (and the cost for defensive or preemptive measures) than the scope for brand differentiation." 87 Unlike current views of trademarks in domain names, a "trademark does not confer a right to prohibit the use of the word or words ... [by others] .... A trademark only gives the right to prohibit the use of it so far as to protect the owner's goodwill against the sale of another's product as his." 88 The Sunrise Policy enables

\footnotetext{
83 Prahl, supra note 60.

84 T. Earl Levere \& Amy R. Tulk, New Generic Top-Level Domains Will Bring New Threats to Trademark Owners, FED. LAW., Oct. 2011, at 16.

$85 I d$.

$\mathbf{8 6}$ With increased numbers of defensive registrations, the number of available second level domains will decrease, leading to a lack of useable namespace for legitimate registrants. In fact, new gTLDs that had no or minimal restrictions "had the lowest number of new domain name registrants and the largest share of registrants that already held over 100 domain names. This suggests that a large number of domain names was registered for defensive purposes." WORLD INTELLECTUAL PROP. ORG.,WIPO ARBITRATION AND MEDIATION CENTER - NEW GENERIC TOP-LEVEL DOMAINS: INTELLECTUAL PROPERTY CONSIDERATIONS (2005 REPORT), http://www.wipo.int/amc/en/domains/reports/newgtld-ip (last visited July 23, 2012).

$\mathbf{8}_{7} I d$.

88 Prestonettes, Inc. v. Coty, 264 U.S. 359, 368 (1924).
} 
trademark holders to reserve their marks first, though, ICANN is promoting the view that a trademark right may in fact allow one use to prohibit other uses of that word.

\section{A Proposal to Mitigate Trademark Issues CAUSED BY ICANN'S .BRAND}

In response to the issues ICANN's program will create, this Note proposes that ICANN first create differentiated online categories by preventing companies and trademark holders from registering .brand gTLDs and by allowing only category-type gTLDs. Second, to create the needed context for trademark coexistence and to reduce chances of consumer confusion, an initial twenty-four category-type gTLDs must be restricted and must not be part of the Sunrise Policy. Finally, to reflect the online context markets and how consumers will interact with them, trademark law must focus on both top-level and secondlevel domains to determine the likelihood of consumer confusion. ${ }^{89}$

\section{A. Creating and Maintaining the Context}

To create the necessary context for trademark coexistence across gTLDs and to reduce concerns of consumer confusion, this Note proposes the following: first ICANN should not approve .brand gTLDs; second, for the remaining category-type gTLDs, ICANN should require registries to place restrictions on who may register second-level domains under certain gTLDs; third, the registries for the restricted gTLDs cannot allow trademark holders to register their marks before the general public; and finally, trademark law must incorporate the context-creating top-level domain in its consumer confusion analysis of trademarks in domain names.

\section{Rejecting .brand}

First, to create context in the DNS, ICANN should reject .brand gTLDs and should instead accept only category-type gTLDs. When "[t]he holder of a domain name gains exclusive rights to use that domain name," a trademark holder controls the top-level, and no other company may register that gTLD. ${ }^{\circ}$ By giving trademark holders

89 Or on the third level, second level, and top-level domains in situations explained below.

90 Anupam Chander, The New, New Property, 81 TEx. L. REv. 715, 775 (2003). 
the "absolute control over uses of their marks," ICANN's acceptance of .brand will prevent companies from creating their own secure location on the Internet and will prevent consumers from easily identifying the trademark holder. ${ }^{11}$ Similar to the concerns over how the "overreliance on the .com TLD may be detrimental to innovation and to the ability of entities to create digital identities," .brand gTLDs reduce innovation and competition because they restrict who represents the brand. 92 Thus, to foster an environment of innovation, competition, and information-conveying trademarks ICANN should not approve .brand gTLDs. 93

\section{Restricting Registration}

Second, to ensure both companies and consumers interact with a context marketplace, ICANN should require that at least the following gTLDs are restricted: .agriculture, .airline, .bank, .car, .clothing, .construction, .doctor, .electronics, .homefurnish, .hospital, .insurance, .lawyer, .lgbt, .love, .manufacturing, .movies, .music, .news, .pharmacy, .realty, .sucks, .theater, .transport, .utilities.

Compared to an open top-level domain, when a gTLD is restricted, "only certain entities meeting certain criteria may register names in them." 94 The registry controlling the top-level domain may create standards and requirements that require the registrant to be members of a particular organization, 95 that require the registrant to have a

\footnotetext{
${ }^{91}$ Stacey L. Dogan \& Mark A. Lemley, A Search-Costs Theory of Limiting Doctrines in Trademark Law, 97 TRADEMARK REP. 1223, 1227 (2007).

$9^{2}$ Thomas, supra note 13 , at 53.

93 Compared to a .brand gTLD which only conveys name-information, a category gTLD such as .financial, indicates to consumers that it serves the financial services industry. If the gTLD requires registrants to provide secure transactions " $t]$ he certification provided in the gTLD name thus provides valuable information to consumers who desire secure financial transactions over the Internet." Borchert, supra note 20, at 549.
}

94 The Management of the Internet Names and Addresses: Intellectual Property Issues, supra note 28.

95. MUSEUM Agreement Appendix $S$, INTERNET CORPORATION FOR ASSIGNED NAMES AND NUMBERS (Nov. 3, 2007),

http://www.icann.org/en/about/agreements/registries/museum/appendix-s-o3novo7en.htm. 
certain type of business, 96 or that a registrant's website contain only a certain type of content. ${ }^{97}$

To decide which category-type gTLDs to restrict, ICANN should use a policy that creates online context-markets resembling how offline context-markets allow trademarks coexistence. ${ }^{8}$ So, this proposal seeks to limit the new restricted gTLDs to markets based on two groups, and the twenty-four gTLDs listed above serve as examples and the building blocks for future restricted category-type gTLDs. The first group is based on the North American Industry Classification System ("NAICS") codes. The NAICS is an internationally recognized classification scheme that focuses on new and emerging industries. The reason for using the NAICS codes is that the NAICS sectors resemble and correlate well with the current list of gTLDs, from information and educational categories to professional services and commercial categories. ${ }^{99}$ Moreover, the NAICS codes serve as functional illustrations for how to group organizations together and how to name these groups as new gTLDs. The second group of new restricted gTLDs is based on popular categories, determined by the likelihood of high amounts of defensive registration. ${ }^{100}$

\footnotetext{
${ }_{96}$ The .coop gTLD requires that the registrant is a cooperative organization or association. Am I Eligible?, .Coop, http://www.nic.coop/eligibility.aspx (last visited on July 23, 2012).

${ }_{97}$ Tralliance Corp., travel Registry Policies, .TRAVEL (Dec. 2007), available at http://www.travel.travel/PDFs/Deco7TravelPolicies.pdf.

98 In fact, online trademark law uses offline trademark law strategies to determine infringement. For instance, in the context of the web, courts tend to use three factors from the eight-factor Sleekcraft test for likelihood of offline consumer confusion. Interstellar Starship Services, Ltd. v. Epix, Inc., 304 F.3d 936, 942 (9th Cir. 2002). Moreover, "the Lanham Act features a "use in commerce' requirement to maintain an infringement claim," Orion Armon, Is This As Good As It Gets? An Appraisal of Icann's Uniform Domain Name Dispute Resolution Policy (Udrp) Three Years After Implementation, 22 REV. LITIG. 99, 107 (2003).

99 Diana Hicks, Structural Change and Industrial Classification, 22 STRUCTURAL CHANGE \& ECON. DYNAMICS 93, 95 (2011).

100 The trademark owners would be able to comment on whether ICANN should accept a certain restricted gTLD. This comment system would allow companies who fall under that particular restricted gTLD to agree or disagree with the proposed gTLD. These comments would act similar to how gTLD applicants for prior gTLDs such as .pro had to explain why the gTLD would be popular. REGISTRYPRO, Registry Operator's Proposal, INTERNET CORP. FOR ASSIGNED NAMES AND NUMBERS,

http://archive.icann.org/en/tlds/pro2/Registry\%200perators\%20Proposal.htm (last visited on Oct. 2, 2000). Additionally, this comment system would also resemble how the current gTLD program's comment system allows individuals to voice their support or
} 
Once this first round of gTLD registration ends, ICANN should continue to follow a policy that focuses on a new gTLDs' ability to create a context-market for trademark differentiation and that assesses the possibility of a high volume of defensive registrations. ${ }^{101}$ First, if a new proposed gTLD is listed as one of the NAICS categories and does not encompass a current gTLD's category then ICANN may allow it and must restrict it to ensure that it acts as a contextmarket. ${ }^{102}$ Second, if a new proposed gTLD is not part of the NAICS, but could lead to high numbers of defensive registrations, then ICANN must restrict that gTLD as well. ${ }^{103}$ Lastly, if a new proposed gTLD does not fall under any of the above-mentioned groups, but is popular, then ICANN may allow it and would not need to restrict it. Therefore, this policy will create an Internet with separate domain name categories corresponding to markets in the offline world, which both companies and consumers can use to distinguish identical trademarks.

\section{Removing the Sunrise Policy}

Third, to ensure legitimate third-parties have access to trademarks, this proposal requires that the restricted gTLDs are not part of the Sunrise Service Policy. Although ICANN's inclusion of the Sunrise Policy prevents illegitimate uses of a company's trademark, the defect with the Policy is that it is incapable "of resolving conflicts among domain name applicants with colorable rights to use a particular name."104

disapproval for an applied-for gTLD. Application Comments Forum, INTERNET CORP. FOR ASSIGNED NAMES AND NUMBERS (2012), https://gtldcomment.icann.org.

101 If companies can register their trademarks under gTLDs such as .sucks, .love, or .lgbt before the general public, legitimate third-party users will be prohibited from utilizing the expanded namespace. Moreover, these types of gTLDs may eventually lose their intended function. Courts may conclude that because the gTLD does not restrict registrants to a particular category resembling the gTLD, the gTLD does not provide a context to distinguish trademark usage. HQM, Ltd. v. Hatfield, 71 F. Supp. 2d 500, 507 (D. Md. 1999).

102 One example is .teachers. Although .edu relates to educational institutions, if a group of teachers wish to create a location devoted to exchanging lesson plans and other teaching resources, then ICANN may allow it.

103 One example is .hurl, like Mcdonalds.hurl, Tacobell.hurl, and Microsoft.hurl.

104 Bruce A. McDonald, International Intellectual Property Rights, 35 INT'L LAW. 465, 481 (2001). 
For example, Amica Insurance would be able to restrict Amica Electronics, AMICA (Automatic Musical Instrument Collector's Association), and Actigift Development, which owns the Amica trademark for lighting and home accessories manufacturing, from moving their identities to ICANN's new gTLD system. Currently, Amica Insurance has applied for the gTLD .amica and may potentially place "amica" in the Trademark Clearinghouse. If Amica Electronics, AMICA, and Actigift Development decide to transition to ICANN's new gTLD system, they may have difficulty registering .amica as a second-level domain because Amica Insurance may have already registered in multiple gTLDs through the Sunrise Service Policy.

Additionally, Amica Insurance may be concerned about consumer confusion if these other Amica brands do transition into the gTLD system because without highly differentiated gTLDs confusion is likely. ${ }^{105}$ In fact, " $[\mathrm{w}]$ hen one trademark owner registers its trademark in one such gTLD and another owner registers an identical or similar mark in another gTLD, the public will not be able to clearly attribute each domain name to a specific trademark owner without checking the web site content."106 Thus, once Amica Insurance receives notification that AMICA has applied for a second-level domain, Amica Insurance may object through the Sunrise Dispute Resolution Policy, in an attempt to block another instance of amica. However, if AMICA wishes to prevent Amica Insurance from registering under .music, AMICA would not succeed, even though AMICA has a legitimate use under .music, because the Sunrise Dispute Resolution Policy only provides protection against non-legitimate third parties. ${ }^{107}$ Therefore, to allow multiple legitimate uses of a trademark, the restricted gTLDs cannot allow trademark holders to register their trademarks before the general public.

\section{Verification}

Following the policies developed for other restricted top-level domains ${ }^{108}$, this Note proposes that the registries for each restricted

\footnotetext{
105 WIPO Arbitration and Mediation Center - New Generic Top-Level Domains: Intellectual Property Considerations, supra note 86.

$106 I d$.

107 INTERNET CORPORATION FOR ASSIGNED NAMES AND NUMBERS, GTLD APPLICANT GUIDEBOOK 296-97 (v. 2012-06-04), available at

http://newgtlds.icann.org/en/applicants/agb.

${ }^{108}$ See generally, . MUSEUM Agreement Appendix S, supra note 95; Tralliance Corp., supra note 97.
} 
gTLD must, at a minimum, institute a three-step process of registrant verification, name verification, and content verification. ${ }^{109}$

\section{a. Registrant Verification}

The first step requires the registry to verify that the registrant is able to register a domain name in the restricted category gTLD. (See Figure 2).

Figure 2:

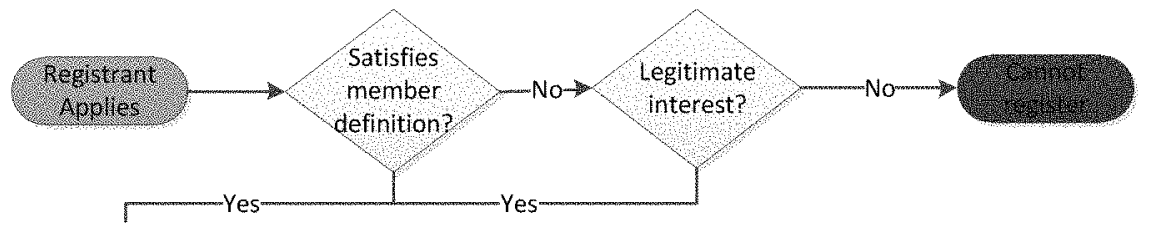

If the gTLD is an industry category and the industry has a membership organization, the registry may elect to use the organization to verify the registrant. ${ }^{110}$ Thus, if the registrant is a member of the organization, the registrant would automatically receive a gTLD member ID and would move to the next verification process. ${ }^{111}$ If the registry allows non-organization members or if the gTLD is a non-industry category, then the registry may develop a membership definition to determine who may register under the restricted gTLD. ${ }^{112}$ Still, if the registrant fails to satisfy the

\footnotetext{
109 Please note: the Verification Process for New Registrants chart is in Appendix A. The full chart has been broken down into its three parts: Registration Verification (Figure 2); Name Verification (Figure 3); and Content Verification (Figure 4).

110 The registry may elect to require the registrant to be an active member within one year.

11 MUSEUM Agreement Appendix S, supra note 95.

112 For example, the charter for .museum allows only granted "entities that are museums.. ., professional associations of museums, or individuals who are professional museum workers." Id. The charter defines museum as "a non-profit making, permanent institution in the service of society and of its development, and open to the public, which acquires, conserves, researches, communicates and exhibits, for purposes of study, education and enjoyment, material evidence of people and their environment." Id.
} 
membership definition, the registry may allow registrants to demonstrate that they have a legitimate interest in registering. ${ }^{113}$

\section{b. Name Verification}

The second step requires the registry to verify that the registrant's applied-for second-level domain name is unique and does not violate trademark holder rights. (See Figure 3).

Figure 3:

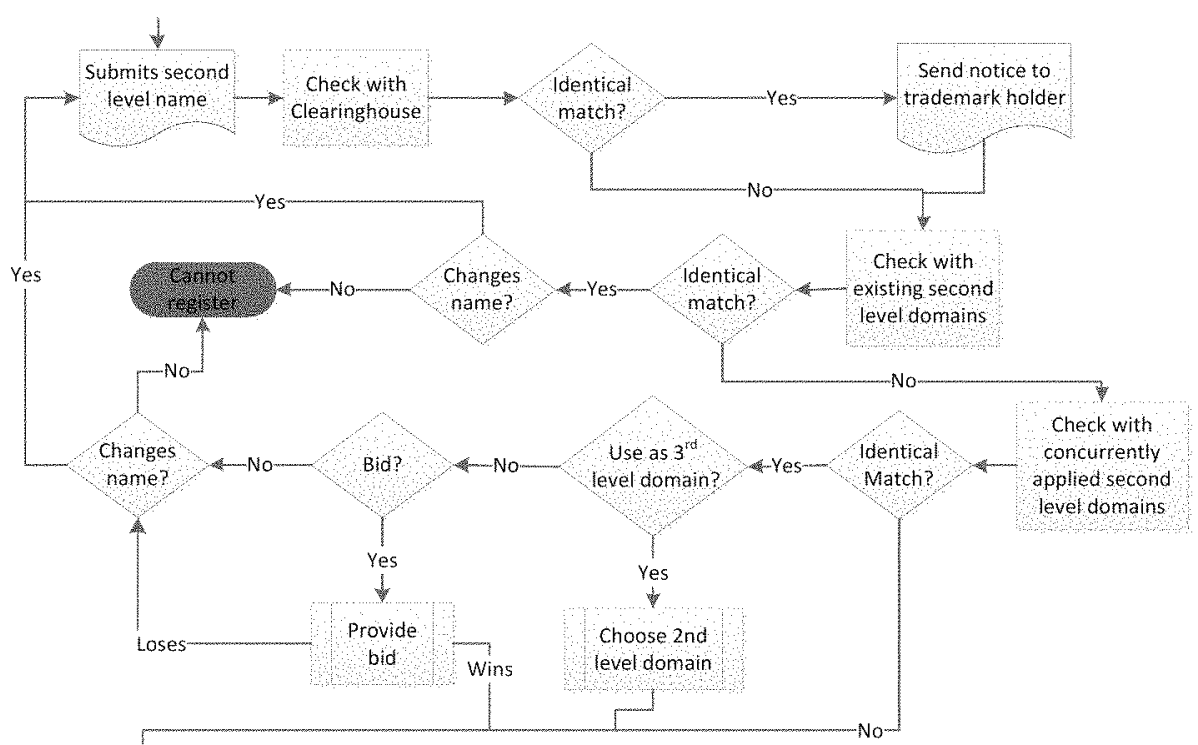

The verification process will work as follows: when a company or individual applies for a second-level domain, the registry must check with the trademark clearinghouse to put the trademark holder on

113 The policies of .museum provide an appropriate approach. If applicants are not members of the museum community, applicants must "provide detailed information about the nature and scope of their museum activities." Summit Strategies International, Evaluation OF THE NEW GTLDS: POLICY AND LEGAL IsSues (July 10, 2004), available at http://archive.icann.org/en/tlds/new-gtld-eval-31augo4.pdf. Thus, for a registrant to be a member of the sucks gTLD, for example, the registrant would demonstrate that the use of the SLDname.sucks will be limited to consumer complaints about the named entity or topic indicated in the second-level domain. 
notice. ${ }^{14}$ Next, the registry must match the applied-for second-level domain with existing and other applied-for second-level domains. If the applied-for name has already been registered, then the registrant must choose another second-level domain name. If the name is available but there are other registrants who have concurrently applied for the same name, then the registry must offer at least the following three resolution options: first, one or more of the registrants may elect to change their applied-for second-level domain name; second, the registrants may decide to register a different second-level domain that will act as a hub for third-level domains, ${ }^{115}$ thereby locking the original applied-for second-level domain name; and third, the registrants may elect to bid on the second-level domain name.

For instance, if Apple, Inc. and Apple Records both apply for "apple" under the .music gTLD, both companies could elect either to change their second-level domain names or to auction off "apple." If neither company wishes to change or bid on the second-level domain name, then both companies would have to select an existing generic word that corresponds to their company's operations as the secondlevel domain name. ${ }^{116}$ Thus, Apple, Inc. may select "computers" and Apple Records may select "records," and the corresponding web addresses would be <apple.computers.music> and <apple.records.music>. The second-level domains of "computer" and "records" would not be controlled by their respective companies. Instead, the third-level domain of "apple" would be controlled by the respective companies, and consumers who type in

114 Unlike ICANN's new program, these restricted gTLDs will not use the Sunrise Policy but will use the trademark claims services policy only. A notice system policy is simpler and fairer than the Sunrise Policy and is consistent with the IP Community's views. The notice system "would put potential registrants on notice of any IP claims, and hence the risk of going forward. It would also afford IP holders an opportunity to begin preparations for a UDRP Complaint, if need be." Id. The registry may elect to have a rolling registration period where companies and individuals submit their applications, move through the verification process, and then receive their domain name throughout the year. Conversely, the registry may elect to institute a registration timetable where companies and individuals file applications at a certain date and for a certain period of time.

\footnotetext{
115 The company or individual must choose a second-level domain that corresponds to their operations.

116 To help facilitate this process, the gTLD registries may elect to reserve commonly used words, similar to .pw's premium name list. .pw Premium Names, LANDRUSH DOMAINS, http://registry.pw/premium-landrush-domains.
} 
$<$ computers.music $>$ or $<$ records.music $>$ will arrive at an index that will list the <.computer.music $>$ and <.records.music $>$ names. ${ }^{117}$

\section{c. Content Verification}

The third step requires the registrant to provide information to the registry that its website will contain information related to the category gTLD and to registrant's company or the second-level domain name. (See Figure 4)

\section{Figure 4:}

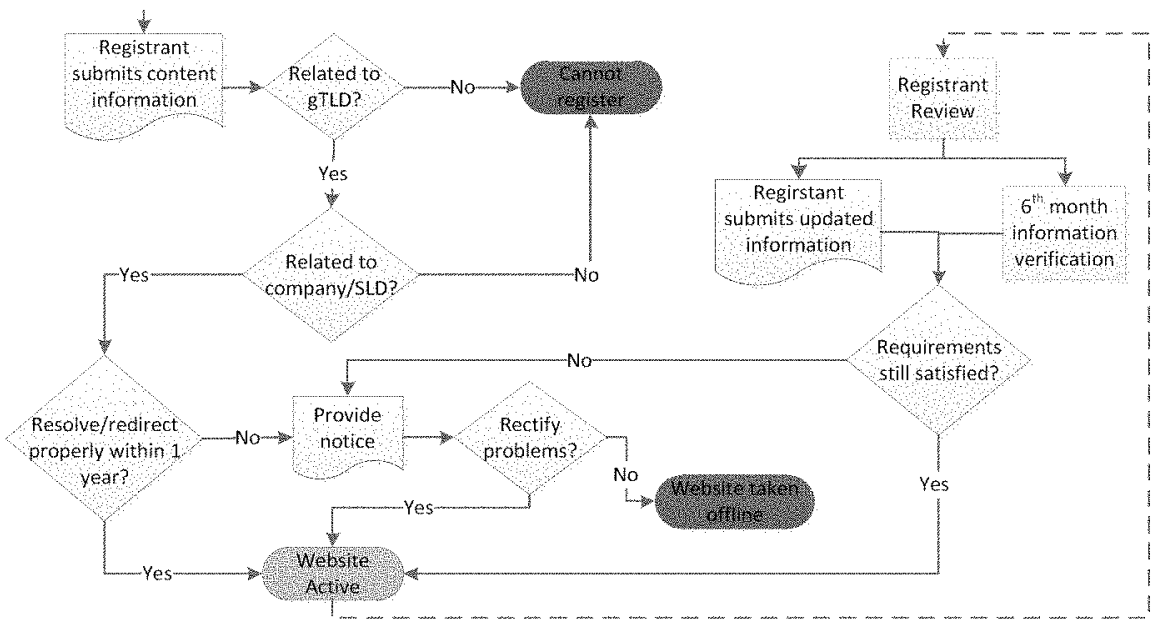

The registrant must demonstrate that the address resolves properly or redirects to a website properly. If the registrant elects to redirect to another website, that website must follow the policies of the content verification process. ${ }^{118}$ If the registrant fails to follow the policies enacted by the registry, the registrant will receive notification to rectify the issues in a reasonable amount of time determined by the registry, after which the website goes off line.

${ }_{17}$ This is a similar approach to how .museum lists all of the museum domain names and redirects the user to the index site when the user types in Approved SLD.museum, such as air.museum or virtual.museum. Index, MUSEDOMA, http://index.museum/fullindex.php (last visited on July 23, 2012). Unlike .museum's index, though, this note proposes that the registry limits to index to the respective second level domain name.

118 This is consistent with .travel's use restrictions as defined in the .travel Registry Policies handbook. Tralliance Corp., supra note 97. 
Finally, to ensure that registrants still comply with the restricted gTLD policies and standards, registrants must update their information once their status as a member of the gTLD category changes, or every six months, depending on which occurs first. (See Figure 4). Additionally, the registries must review the registrant's information and website content, every six months for instance, to ensure that the registrants are still part of the gTLD category and that their websites satisfy the gTLD content standards.

\section{B. Enforcing the Context}

To reflect how companies and consumers will interact with this new context marketplace, trademark law must analyze the domain names together to determine whether consumer confusion is likely to occur. As discussed supra Section I.C.2, a semiotic analysis reveals how best to ensure identical trademarks can coexist on the Internet. Trademark law is "always applied in the context of how a consumer would encounter the mark." 119 When consumers experience trademarks in different markets, they can differentiate between the two uses; they can determine that one use of a trademark refers to one company, while the other identical trademark refers to a completely different company. ${ }^{120}$

Trademark law must also change to recognize that gTLDs may provide additional information-and context-to the rest of the domain name. Following the semiotic analysis, this proposal creates context-markets enabling consumers to differentiate between identical trademarks. To maintain these newly created contextmarkets, this proposal recommends that trademark law focus on both the trademark and the words surrounding the trademark in determining whether there is a likelihood of confusion. With the context created by the category-type gTLDs, trademark law will once again focus on the context in which the trademark is used, because these restricted category-type gTLDs are not abstract. ${ }^{121}$ Unlike open

119 Christine Haight Farley, Convergence and Incongruence: Trademark Law and Icann's Introduction of New Generic Top-Level Domains, 25 J. MARSHALL J. COMPUTER \& INFO. L. 625,631 (2009).

${ }^{120}$ Like semiotics, trademark law focuses on context; it seeks to "lessen consumer search costs by making products and producers easier to identify in the marketplace [and to] encourage producers to invest in quality by ensuring that they, and not their competitors, reap the reputation-related rewards of that investment." Barton Beebe, The Semiotic Analysis of Trademark Law, 51 UCLA L. REV. 621, 623 (2004).

121 Farley, supra note 119. 
gTLDs or even gTLDs like .xxx and .mobi, the proposed restricted gTLDs are not inconsequential because they provide necessary information to help determine the source or sponsor of the secondlevel domain. ${ }^{122}$ Therefore, trademark law must not ignore the gTLD and must not focus only on the use of the trademark in the secondlevel domain. Trademark law must instead use the context-creating category gTLDs to determine the use of the trademark and the likelihood of confusion, because the coexistence of trademarks and trademark differentiation work "only when gTLDs are restricted to limited and clearly circumscribed specific purposes." 123

\section{Applying the Proposal to Nissan.com: A Re-Evaluation}

To show how this proposal will reduce chances of consumer confusion, this Note will apply the proposed context creating and enforcement strategies to Nissan Motor Co. v. Nissan Computer Corp., 378 F.3d 1002, 1007 (9th Cir. 2004). In Nissan, the use of "nissan" in the web address <www.nissan.com> infringed Nissan Motor's trademark because the court saw confusion between the trademark Nissan Motors and the web address <www.nissan.com $>.{ }^{124}$ The confusion arose because the consumers were captured by the "nissan" in the domain name: they saw the trademark, became interested in Nissan's vehicles and in finding more about Nissan Motor, and then clicked on <www.nissan.com $>.{ }^{125}$

This issue of confusion, though, is easily remedied with this Note's proposal in which Nissan Motor registers <nissan.car> and Nissan Computer registers <nissan.electronics>. To register $<$ nissan.electronics $>$, Nissan Computer would have to satisfy the verification process. First, Nissan Computer would need to meet .electronics membership definition, such as by proving that it is a

\footnotetext{
122 With the restricted gTLDs, there will not be "a limited number of gTLDs that almost every company uses" and thus, courts and UDRP panels should use the gTLDs in evaluating the second-level domain "for the purposes of determining similarity between two marks." Jonathan L. Schwartz, Making the Consumer Watchdog's Bark As Strong As Its Gripe: Complaint Sites and the Changing Dynamic of the Fair Use Defense, 16 ALB. L.J. SCI. \& TECH. 59, 76 (2006).

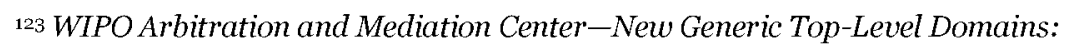


company that sells computers. Second, Nissan Computer would have to submit its second-level domain name to the registry. The registry would check with the Trademark Clearinghouse and if "nissan" exists, the registry would send notification to Nissan Motor. If "nissan" is available under .electronics and no other registrant has concurrently applied for "nissan," then Nissan Computer would be able to register $<$ nissan.electronics>. Lastly, Nissan Computer's website would have to resolve correctly or redirect to a computer-selling website within one year, and it would have to demonstrate that the website focuses on selling computers under its name, Nissan Computer. If Nissan were to change its focus, then Nissan would have to submit that information to the registry to remain in compliance.

After this verification process and after <nissan.electronics> is active, when a consumer wishes to search for information about Nissan cars, the consumer would be able to tell the difference between <nissan.car> and <nissan.electronics> and would conclude that $<$ nissan.car $>$ relates to automobiles. Thus, a likelihood of confusion would not exist, because the gTLDs would indicate to the consumer what type of content the website contains and how the second-level domain mark is related to that content.

\section{Advantages to the Proposal}

Unlike ICANN's new gTLD program this Note's proposal will create more benefits for both companies and consumers because this proposal will allow companies to better maintain their offline presence online, will reduce chances of consumer confusion by creating separate markets online, and will promote the goals of ICANN and its gTLD program.

\section{Trademark Coexistence}

First, this proposal allows identical trademarks to coexist online. This will in turn allow companies to maintain their brand identities better than ICANN's gTLD program, because this proposal will provide trademark holders the equal ability to register their brand identity. Trademark holders will not be able to monopolize on their trademarks because this proposal creates differentiated markets based on category-type gTLDs. Thus, Delta Air Lines, Delta Faucet, and Delta Insurance would all be able to use "delta" in recognizably different category markets.

Moreover, without the Sunrise Policy, companies moving to the new category markets will be able to transition without fear that their 
company name has been taken by a trademark holder that is simply seeking to block potentially infringing uses. For example, Amica insurance would not be able to register under .electronics, .homefurnish, .manufacturing, or .music because Amica Insurance is an insurance company. Thus, Amica Engineering, AMICA, and Actigift Development would all have the ability to register in their respective categories with the knowledge that they will be part of a defined group of companies. ${ }^{126}$

\section{Reduction of Consumer Confusion Concerns}

Second, compared to ICANN's gTLD program, this proposal reduces instances of consumer confusion. When gTLDs are restricted, UDRP cases decrease because trademark holders do not need to worry that others will violate their trademark rights. ${ }^{127}$ Unlike open gTLDs, restricted gTLDs limit the chances of consumer confusion and trademark infringement because registrants must meet the strict eligibility requirements before they can register a second-level domain. Even though .museum "does not offer protective registrations for trademark holders," the absence of UDRP proceedings for .museum indicates that trademark infringement is not an issue for .museum. ${ }^{128}$ Although there is a <national.corvette.museum> website, General Motors has not sought legal action to transfer the domain because there is "no evident connection to the car manufacturer."129 The TLD .museum, though, is not an anomaly. In fact, between 1999 and 2011, there have been o UDRP proceedings for .coop, 1 for .aero, 5 for .cat, 13 for .travel, 1 for .xxx, 18 for .pro, and 25 for .name..$^{130}$ Thus, consumer confusion through this proposal is not very likely because it creates context-markets for companies and consumers to interact, knowing that the websites under the restricted gTLD will relate to the category name.

\footnotetext{
${ }^{126}$ Amica Electronics would register as < amica.electronics>, AMICA would register as

<amica.music>, and Actigift Development would register as < amica.homefurnish >.

127 Summit Strategies International, supra note 113.

${ }^{128} \mathrm{Id}$.

$129 \mathrm{Id}$.

130 All gTLDs by Year and Total, WORLD INTELLECTUAL PROPERTY ORGANIZATION, http://www.wipo.int/amc/en/domains/statistics/gtlds.jsp (last visited June 23, 2012).
} 


\section{Promoting the Goals of ICANN}

Lastly, this proposal reflects ICANN's mission and the goals of the new gTLD program. When ICANN was formed, it agreed in a Memorandum of Understanding to promote "the management of the DNS in a manner that will permit market mechanisms to support competition and consumer choice in the technical management of the DNS." ${ }^{31}$ In accordance with this purpose, ICANN anticipates that by expanding the top-level domain namespace, the new gTLD program will encourage diversity, and competition will "enhance the utility of the DNS, and will create options for consumers. ${ }^{132}$

Unlike .brand gTLDs, though, the restricted category-type gTLDs promote ICANN's goals because they focus on creating a diverse and competitive community of companies or individuals. Category labels allow consumers to group individual websites together and to infer that the websites will relate to the category. ${ }^{133}$ Categories enable consumers to perform this grouping because users will "deal with the characteristics of the group as a whole," instead of focusing on the individual websites separately. ${ }^{134}$ Consequently, users who see category-type gTLDs will not associate the second-level domains with a singular company or individual. ${ }^{135}$ Rather, they will come to

\footnotetext{
${ }^{131}$ Memorandum of Understanding Between the U.S. Department of Commerce and Internet Corporation for Assigned Names and Numbers, INTERNET CORPORATION FOR ASSIGNED NAMES AND NUMBERS (Dec. 31, 1999),

http://www.icann.org/en/about/agreements/mou-jpa/icann-mou-25novg8-en.htm.

${ }^{132}$ INTERNET CORPORATION FOR ASSIGNED NAMES AND NUMBERS, GTLD APPLICANT GUIDEBOOK 2 (v. 2012-06-04), available at http://newgtlds.icann.org/en/applicants/agb.
}

133 Takashi Yamauchi \& Na-Yung Yu, Category Labels Versus Feature Labels: Category Labels Polarize Inferential Predications, 36 MEMORY \& COGNITION 544, 551 (2008).

134 Id.

135 In fact, .brand applications can only promote a singular company. The applicants seem to recognize this because the applications tend to focus on protecting the trademark holder's online presence and identity, expanding its marketing and promotion efforts, and creating a location to consolidate its activities. For example, Guardian Life Insurance recognizes that a .brand gTLD will not promote choice and competition. In its application, it states that "[ $\mathbf{t}]$ he success of .GUARDIAN will not be measured by the number of domain names registered, but rather by the levels of consumer recognition and trust that are placed in the gTLD." Application Details: GUARDIAN, INTERNET CORPORATION FOR ASSIGNED NAMES AND NUMBERS (2012), http://gtldresult.icann.org/applicationresult/applicationstatus/applicationdetails/1038. Thus, .brand gTLDs will not encourage diversity and choice among the gTLDs because, when these gTLDs only allow the 
associate the gTLD with websites that share the same information or are part of the same, shared community. ${ }^{136}$ As a result, companies will choose to be a part of a category to promote their businesses and consumers will visit those categories expecting to find websites matching the category-market. Thus, this proposal advances ICANN's goals by creating a system in which consumers and companies associate categories with markets and in which they interact inside those markets.

\section{CRITICISMS TO ELIMINATING .BRAND GTLDS AND REQUIRING TRADEMARK LAW TO REFOCUS HOW IT ANALYZES TRADEMARKS IN DOMAIN NAMES}

To further demonstrate how useful this proposal is, this section will address possible objections to the proposal, which include: issues with promoting a system that restricts diversity by limiting a company's choice to register is trademark as a gTLD, concerns about the lackluster numbers of registrations under past restricted gTLDs, and a recent study that showed Internet users may not directly interact with domain names as much as before.

\section{A. Limiting the Freedom of Choice and Diversity}

First, .brand applicants may argue that limiting the new gTLDs to category-types restricts their right of equal access to the online marketplace, while allowing them to register .brand gTLDs will increase the diversity of top-level domains. ${ }^{137}$ ICANN's program policies even seem to agree with this objection: one of the reasons ICANN has encouraged companies to submit international top-level

trademark holder and its affiliates to register, other potential registrants have no ability and no reason to attempt to register under .brand gTLDs.

${ }^{136}$ Top Level Spectrum, Inc.'s application .sucks argues that "Internet users browsing and using sites with a .sucks extension will be confident that the website they are navigating will be related to share or browsing opinions that suck." Application Details: SUCKS, INTERNET CORPORATION FOR ASSIGNED NAMES AND NUMBERS (2012),

http://gtldresult.icann.org/application-result/applicationstatus/applicationdetails/1070.

${ }_{137}$ The choice and diversity that ICANN's program seems to give companies is how they can appear in the DNS. Through the program, they can own a gTLD and a domain name under traditional gTLDs like .com, .org, or .net. For example, "[a] corporation will be able to own a domain such as www.google.com and also the .google gTLD." Prahl, supra note 60, at 1758 . 
domains is to promote a diverse domain space. ${ }^{138}$ Therefore, the proposal may reduce diversity because it seeks to limit the types of available gTLDs.

Although the proposal does prohibit .brand gTLDs, the proposal encourages diversity among the gTLDs and increases the value of the Internet for companies and consumers. The Internet's value comes from its ability to connect people. The "more people that are connected to the Internet, the more valuable the connection is to each of the members." 139 Thus, a fair program should take "into account the interests of both trademark holders and the Internet community at large, as well as the interests of both the wealthy and the poor," to ensure that a diverse range of trademark users have access to the new context market. ${ }^{140}$ Generic word categories define classes of goods and not specific companies. ${ }^{141}$ So even though domain names are monopolies "on a given word or set of words," generic words that act as category labels increase equal access to the use of a trademark. ${ }^{142}$

Consequently, with more gTLDs that allow for identical secondlevel domains, the Internet and the domain namespace will become more diverse. Consumers will be able to engage more companies across more gTLDs, instead of being forced to engage one company at one gTLD. ${ }^{143}$ Moreover, companies who share the same trademark can

${ }_{138}$ Unlike traditional ICANN-approved domain names, Internationalized Domain Names (IDNs) will allow companies and registrants to create domain names using "local language characters or letter equivalents." Schierman, supra note 53.

139 Mark A. Lemley, Antitrust and the Internet Standardization Problem, 28 CoNN. L. Rev. 1041, 1045 (1996).

140 Minqin Wang, Regulating the Domain Name System: Is the ".biz" Domain Name Distribution Scheme an Illegal Lottery?, 2003 U. ILL. L. REV. 245, 246 (2003).

${ }^{141}$ Liquid Controls Corp. v. Liquid Control Corp., 802 F.2d 934, 936 (7th Cir. 1986).

${ }^{142}$ Stuart A. Weinstein, The Cyberpiracy Prevention Act: Reconciling Real Space Sectoral and Geographic Distinctions in the Use of Internet Domain Names Under the Lanham Act, 9 U. MIAMI BuS. L. REV. 145, 157 (2001).

143 In focusing on blocking other potential legitimate uses in the top and second-levels, .brand applicants are attempting to focus a consumer's attention to a sole instance of the brand. Applicants for .brand gTLDs may be hoping that consumers will associate the mark with a secure and centralized location so deeply "as to pass below conscious thought and generate an unthinking or 'Pavlovian' ... response." Once consumers reach this level, their visits to the .brand gTLD will become mere habit. Glynn S. Lunney, Jr., Trademark Monopolies, 48 EMORY L.J. 367, 428 (1999). Nevertheless, this approach perpetuates the flat domain namespace and does not increase network externalities; consumers will only interact with one company instead of multiple companies interacting with multiple 
promote their brands and vie for consumer loyalty more equally. Although charging $\mathbf{\$ 1 8 5 , 0 0 0 ~ " f o r ~ m e r e l y ~ t h e ~ r i g h t ~ t o ~ s u b m i t ~ a n ~}$ application effectively places a barrier to entry for . .." groups who have limited resources to promote their company or brand, individuals can register second-level domains for less than \$200 dollars. ${ }^{144}$ Therefore, with companies and individuals registering under categories, "Internet users and consumers would be more likely to recognize these gTLDs and use them as indexing tools in browsing the Internet." 145 This avoids "conceding that ownership of a trademark gives one the exclusive right to use the word on the Internet." 146 Additionally, this fosters a DNS that encourages consumers to view trademarks and markets similar to the offline world; "just as we have lots of different Acme trademarks out here in meat space, there can be lots of different acme-dot domains in cyberspace."147

\section{B. Registrants Are Not Interested in Restricted gTLDs}

Second, critics might argue that the proposal will not increase gTLD competition because the imposed restrictions will stifle interest in the proposed gTLDs. For example, even though .museum was meant to provide an online community for museums, only 1.4 percent (556/40,00o) of eligible museum registrants registered a second-level domain. ${ }^{148}$ Therefore, based on the history of the restricted gTLD, the

consumers under category-type gTLDs. Heather N. Mewes, Memorandum of Understanding on the Generic Top-Level Domain Name Space of the Internet Domain Name System, 13 BERKELEY TECH. L.J. 235, 243 (1998).

${ }^{144}$ Jay P. Kesan \& Rajiv C. Shah, Fool Us Once Shame on You-Fool Us Twice Shame on Us: What We Can Learn from the Privatizations of the Internet Backbone Network and the Domain Name System, 79 k 89, 203 (2001). For instance, Moniker.com sells domains between \$7.00 and \$100. Domain Name Products, MONIKER (2012), https://www.moniker.com/domainnameregistrationdomainnames.jsp. DomainMonster.com sells domains between $\$ 10$ and $\$ 100$. Domain Price List, DOMAINMONSTER.COM (2012), http://www.domainmonster.com/domains.

145 Heather N. Mewes, Memorandum of Understanding on the Generic Top-Level Domain Name Space of the Internet Domain Name System, 13 BERKELEY TECH. L.J. 235, 244-247 n.51 (1998).

146 Jessica Litman, The DNS Wars: Trademarks and the Internet Domain Name System, 4 J. SMALl \& EmERging BuS. L. 149, 164 (2000).

147 Id. at 165 .

148 Katz, supra note 31. 
proposed restricted gTLDs may not gather enough valuable interest to even become locations for companies and consumers to interact.

Nevertheless, the low rate of registrations for restricted gTLDs, such as .museum, is more the result of failing to market the gTLD and failing to provide valuable benefits than requiring registrants to satisfy certain criteria. ${ }^{149}$ Without educating potential registrants about the benefits of a gTLD that restricts "second-level domains to a collection of similar organizations whose web sites are of interest to large communities of potential site visitors," the gTLD will remain unknown and under utilized; yet, this is not because of the restrictions imposed on the registrants. ${ }^{150}$ In fact, compared to .museum, .gov, another restricted gTLD, "has been successful in the sense that it has a recognized meaning among many members of the public," in part because "the U.S. federal government has undertaken efforts to promote the use and recognition of .gov."151 Therefore, even though the proposal imposes restrictions on the gTLDs, the registries must actively promote the gTLD and highlight its advantages over currently existing gTLDs or newly approved ones.

For example, every available gTLD has a value based on its functional utility. ${ }^{152}$ The closer a gTLD is to a memorable and usable word, the more value the gTLD will have. If one gTLD has more value than other gTLDs, then the registrant may begin searching for prices at various registrars. ${ }^{153}$ Therefore, gTLDs will have value competition increases among gTLDs because registrants will seek gTLDs that provide useful benefits at reasonable costs. ${ }^{154}$

Accordingly, the proposed restricted gTLDs provide value to the Internet and consumers because their usability will increase

\footnotetext{
149 Id.

${ }_{150} \mathrm{Id}$.

${ }^{151} I d$.

${ }_{152}$ Karl M. Manheim \& Lawrence B. Solum, An Economic Analysis of Domain Name Policy, 25 HASTINGS COMM. \& ENT. L.J. 359, 388-95 (2003).
}

153 Registrars may compete amongst themselves through competitive pricing and benefits schemes, such as third-level name blocking (EnCirca) and free URL forwarding services (GoDaddy.com). Katz, supra note 31.

154 The low registration levels of .aero indicate that "many airports do not believe that .aero registrations generate benefits greater than their costs," even though the cost of a two-year registration ranges from $\$ 130$ to $\$ 198$. $I d$. 
competition among gTLDs. ${ }^{155}$ A category-type gTLD has value because it provides a location reference for consumers and enables companies to use it as part of their name and online trademark promotion. ${ }^{156}$ For example, a construction company may wish to be part of a .construction gTLD because, unlike open and context-less gTLDs like .com, .construction shows that the company is part of the construction-related community. Additionally, consumers will be able to remember the company and its business easily. ${ }^{157}$ Therefore, contrary to the objection, the proposed gTLDs will increase competition among registries because a company will seek the benefits of memorable and marketable gTLDs that emphasize the company's type of business.

\section{Online Consumers No Longer Care About Domain Names}

Lastly, critics may argue that the proposal does not reflect accurately how consumers actually interact with websites. Currently, consumers use a combination of domain type-in and search engines to locate websites. ${ }^{158}$ Even though search engine results provide the website's domain name, they "deemphasize the relevance of domain names by diminishing the part that they play in guiding a user to content." 159 The search results prominently feature the title, followed by a brief excerpt from the website; the domain name, however, is small and located between the title and the excerpt. ${ }^{160}$ Moreover, "eye tracking experiments have revealed that the majority of users who view such search results spend little or no time looking at the site

\footnotetext{
$155 \mathrm{Id}$.

${ }_{156} \mathrm{~A}$.brand gTLD does not bring value into the gTLD market because it is too unique and limited. Consumers may believe that Apple, Inc. may control the .apple websites; yet companies will not seek to register under apple because they cannot use it as part of their trademark's online promotion without conflicting with Apple's online promotion.

Moreover, companies will not seek to register under .apple because consumers will only associate .apple with Apple's products and services. Therefore, .brand gTLDs do not increase competition among the registries.
}

157 Karen E. Klein, The Latest Domain-Name Gold Rush, BUSINESS WEEK (June 4, 2012), http://www.businessweek.com/articles/2012-06-04/the-latest-domain-name-gold-rush.

${ }_{158}$ Thomas, supra note 13 , at 49.

$159 \mathrm{Id}$. at 50 .

$160 \mathrm{Id}$. at 49. 
address portion of each search result;" instead, before clicking on a result, they "tend to scan from title to title and snippet to snippet in an abbreviated fashion."161 Therefore, critics may state that a proposal which seeks to change how trademark law examines domain names is ineffective.

Nevertheless, companies and trademark law currently focus on consumers interacting with domain names. Some web users may not focus on the domain name, but when web users do focus on the domain name, trademark law does recognize that they may view the combination of the trademark with the other elements surrounding it. For instance, when consumers interact with .com websites, they may believe they are commercial websites because the .com gTLD signifies a website's commercial nature, and "web users often assume, as a rule of thumb, that the domain name of a particular company will be the company name followed by '.com'." ${ }^{162}$ Moreover, when a registrant registers a trademark under the .net gTLD for communicative and non-commercial purposes, trademark law may allow the coexistence of < trademark.com> and <trademark.net> because the registrant has not usurped the trademark holder's ability to obtain a .com domain name. ${ }^{163}$ Therefore, given that trademark law still analyzes domain names to determine consumer confusion, trademark law must be prepared for situations when a company believes that consumer confusion may occur at the domain name level. To ignore this would not mitigate the trademark concerns prevalent in ICANN's gTLD program.

Conversely, the proposal seeks to mitigate the trademark concerns because it does recognize trademark law's current approach. Even though search results do not prominently feature domain names, "[d]omain names are the road signs of cyberspace and the removal of these signs makes it significantly harder for individuals to find the information they seek: it is like trying to navigate the road without any

\footnotetext{
161 Id.

162 Brookfield Commc'ns, Inc. v. West Coast Entm’t Corp., 174 F.3d 1036, 1044-45 (9th Cir. 1999). Additionally, the Ninth Circuit has said "<.net> applies to networks and <.com> applies to commercial entities." Avery Dennison Corp. v. Sumpton, 189 F.3d 868, 880 (9th Cir. 1999).

163 Bridgestone Firestone, Inc., Bridgestone/Firestone Research, Inc., and Bridgestone Corporation v. Jack Myers, No. D2000-0190 (Haviland, Arb.), available at http://www.wipo.int/amc/en/domains/decisions/html/2000/d2000-0190.html.
} 
signposts."164 Therefore, the proposal recognizes how trademark law currently views trademarks in domain names and presents a workable and effective way to ensure that the functions of trademarks and the goals of ICANN's gTLD program are not compromised.

\section{CONCLUSION}

This Note provides a way for ICANN to solve the disastrous problems plaguing the new gTLD program. By eliminating .brand gTLDs from ICANN's new program, the Internet can actually begin to expand as ICANN envisioned. Identical trademarks can share and coexist in this newly expanded domain name space. Additionally, by imposing restrictions on a few of the 500 category-type gTLDs, this proposal supports a useful and beneficial Internet. It encourages registrants to seek out new gTLDs that reflect their business type or future website content, instead of seeking out every new gTLD and defensively registering their trademark. Lastly, in promoting a new method to determine consumer confusion in domain names, competitive gTLD schemes will remain a viable solution to increasing registry competition and in helping trademark holders maintain their online identity.

\footnotetext{
${ }^{164}$ Andrew D. Murray, Regulation and Rights in Networked Space, 30 J.L. SOC’Y 187, 210-
} 11 (2003). 
APPENDIX A

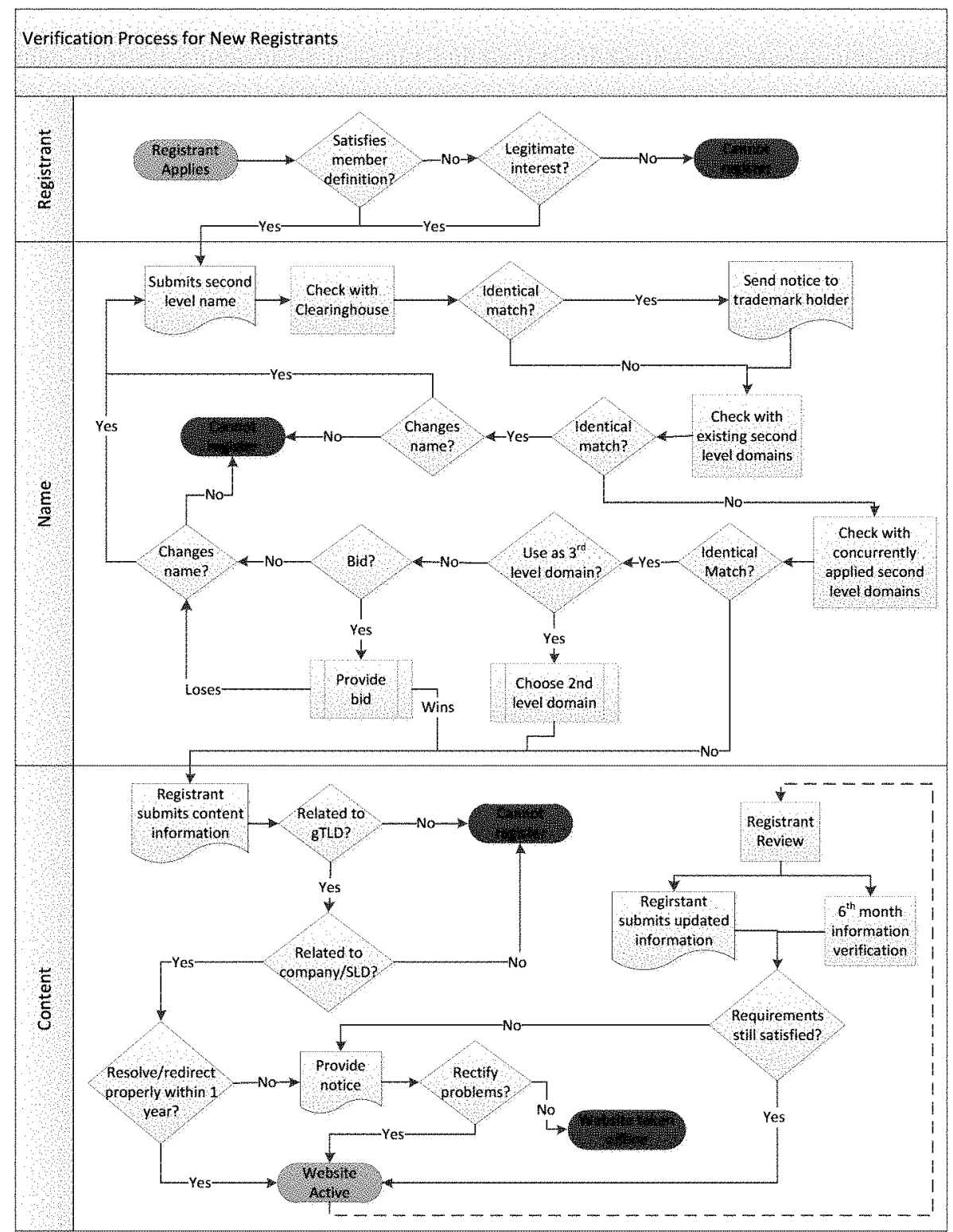


